\title{
Regional scale effects of the aerosol cloud interaction simulated with an online coupled comprehensive chemistry model
}

\author{
M. Bangert, C. Kottmeier, B. Vogel, and H. Vogel \\ Institute for Meteorology and Climate Research, Karlsruhe Institute of Technology, Karlsruhe, Germany \\ Received: 21 October 2010 - Published in Atmos. Chem. Phys. Discuss.: 4 January 2011 \\ Revised: 13 April 2011 - Accepted: 28 April 2011 - Published: 11 May 2011
}

\begin{abstract}
We have extended the coupled mesoscale atmosphere and chemistry model COSMO-ART to account for the transformation of aerosol particles into cloud condensation nuclei and to quantify their interaction with warm cloud microphysics on the regional scale. The new model system aims to fill the gap between cloud resolving models and global scale models. It represents the very complex microscale aerosol and cloud physics as detailed as possible, whereas the continental domain size and efficient codes will allow for both studying weather and regional climate. The model system is applied in a first extended case study for Europe for a cloudy five day period in August 2005.
\end{abstract}

The model results show that the mean cloud droplet number concentration of clouds is correlated with the structure of the terrain, and we present a terrain slope parameter TS to classify this dependency. We propose to use this relationship to parameterize the probability density function, PDF, of subgrid-scale cloud updraft velocity in the activation parameterizations of climate models.

The simulations show that the presence of cloud condensation nuclei $(\mathrm{CCN})$ and clouds are closely related spatially. We find high aerosol and $\mathrm{CCN}$ number concentrations in the vicinity of clouds at high altitudes. The nucleation of secondary particles is enhanced above the clouds. This is caused by an efficient formation of gaseous aerosol precursors above the cloud due to more available radiation, transport of gases in clean air above the cloud, and humid conditions. Therefore the treatment of complex photochemistry is crucial in atmospheric models to simulate the distribution of CCN.

The mean cloud droplet number concentration and droplet diameter showed a close link to the change in the aerosol. To quantify the net impact of an aerosol change on the pre-

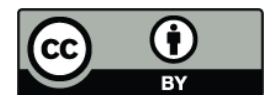

Correspondence to: M. Bangert (max.bangert@kit.edu) cipitation we calculated the precipitation susceptibility $\beta$ for the whole model domain over a period of two days with an hourly resolution. The distribution function of $\beta$ is slightly skewed to positive values and has a mean of 0.23 . Clouds with a liquid water path LWP of approximately $0.85 \mathrm{~kg} \mathrm{~m}^{-2}$ are on average most susceptible to aerosol changes in our simulations with an absolute value of $\beta$ of 1 . The average $\beta$ for LWP between $0.5 \mathrm{~kg} \mathrm{~m}^{-2}$ and $1 \mathrm{~kg} \mathrm{~m}^{-2}$ is approximately 0.4 .

\section{Introduction}

The interaction of aerosol particles with clouds is still one of the largest uncertainties in modern climate studies (Forster et al., 2007). Depending on their chemical composition and size, atmospheric aerosol particles can act as cloud condensation nuclei (CCN) during cloud formation. Therefore, they determine the initial size distribution of the cloud droplets (Twomey, 1959). As a consequence, the aerosol particles have an influence on the optical properties and microphysical processes of clouds.

Previous numerical studies followed a variety of approaches on different scales to improve the understanding of the aerosol cloud interactions. The impact of aerosol changes on precipitation is thereby one of the most discussed processes (Khain, 2009; Stevens and Feingold, 2009; Small et al., 2009; Levin and Cotton, 2009; Rosenfeld et al., 2008) in the scientific literature. Simulations of single clouds and cloud clusters showed that depending on the cloud type the influence of aerosol changes on cloud microphysics can affect precipitation amounts very differently (Khain, 2009 and references therein). Due to their comprehensive cloud microphysics and the used fine grid meshes such simulations are limited to small domains and short time scales. Stevens and Feingold (2009) pointed out that the limitation to small scales

Published by Copernicus Publications on behalf of the European Geosciences Union. 
is a major reason for differences in the net aerosol effect on the precipitation amount since macrophysical buffers exist that cannot be considered.

In contrast to small scale models global scale models investigate the possible impact of the aerosol particles on the global climate (Quaas et al., 2009; Pringle et al., 2009; Storelvmo et al., 2008; Lohmann et al., 2007) but are limited to coarse spatial resolutions. Therefore, the inhomogeneous distributions of clouds and aerosol particles cannot be resolved in such models.

In most cloud-resolving models, the aerosol particles are represented in a very general manner by prescribing distributions of particles or CCN-spectra and neglecting aerosol formation and dynamics. This can be justified by usually very small model domains and the need of well-defined CCN conditions for the sensitivity studies. In contrast, modern global climate models are able to consider aerosol composition and dynamics but are forced to use pragmatic implementations for aerosol and gas phase chemistry because of the computational burden.

The distribution of aerosol and clouds are also influenced by mesoscale features like e.g., anthropogenic and natural emissions, land sea distribution and topography. Recent studies have shown the ability of mesoscale models to represent the interaction of aerosol particles with clouds and the advantages of their use (Cheng et al., 2010; Ntelekos et al., 2009; Guohui et al., 2009; Muhlbauer and Lohmann, 2009; Ivanova and Leighton, 2008). With mesoscale models it is possible to represent aerosol and clouds with a comparable level of complexity; yet, just a few models are able to treat all of these processes together (Zhang, 2008).

Because a significant fraction of global $\mathrm{CCN}$ is produced by nucleation and condensation of aerosol particles from gaseous precursors (Merikanto et al., 2009), the treatment of detailed gas phase chemistry is crucial in the estimation of the impact of anthropogenic emissions on clouds and precipitation.

In this study we simulate the spatial distributions of aerosol particles and clouds as well as their interaction on the regional scale with a coupled mesoscale atmosphere and chemistry model. We investigate which processes and feedbacks occur on this scale to help close the gap between the scale of single cloud studies and global models in our understanding of aerosol cloud interactions.

We use the online coupled mesoscale atmosphere and chemistry model COSMO-ART (Vogel et al., 2009) to calculate the distribution and chemical composition of the aerosol particles and, therefore, the distribution of available $\mathrm{CCN}$ on the basis of natural and anthropogenic emissions and on the basis of detailed calculations of the gas phase chemistry. We extended the cloud scheme of the model to include the impact of aerosol particles on the warm cloud microphysics. With this model we are able to simulate the gases, aerosols, and clouds with a comparable level of complexity on the regional scale.
After a short description of the treatment of the aerosol cloud interactions in the model, we present results of simulations for the domain of Europe. We discuss the distributions of aerosol particles, $\mathrm{CCN}$, and clouds on the regional scale and their correlations amongst one another as well as the correlation with the orographic conditions. At last we address the net impact of the aerosol on precipitation for a period of two days. We calculate the precipitation susceptibility for the whole model domain in an hourly resolution to investigate and quantify the net response of the precipitation on the regional scale to a change in the aerosol.

\section{Model description}

Studying the interaction of aerosol particles and the atmosphere with a numerical model at a specific scale requires the treatment of the relevant physical, chemical, and aerosol dynamical processes at a comparable level of complexity. To fulfil these requirements we developed the model system COSMO-ART for the regional to continental scale. COSMO-ART is based on the non-hydrostatic weather forecast model COSMO (Consortium for Small-scale Modelling, Steppeler et al., 2003) of the Deutscher Wetterdienst (DWD) and is online coupled with comprehensive modules for gas phase chemistry and aerosol dynamics. ART stands for Aerosols and Reactive Trace gases. The online coupling is realized in a consistent way using the same grid for all scalars, e.g. temperature, humidity, and gas phase concentrations. For processes affecting all scalars, as for example advection, the same numerical schemes are applied.

COSMO-ART includes complex photochemistry to calculate the temporal and spatial distribution of the gaseous precursors of secondary aerosol particles. An extended version of MADEsoot (Riemer et al., 2003) represents the aerosol population within COSMO-ART by several overlapping lognormal distributions

$n_{l}(D)=\frac{1}{D} \frac{N_{l}}{\sqrt{2 \pi} \ln \sigma_{l}} \exp \left(\frac{\ln ^{2}\left(D / \bar{D}_{l}\right)}{2 \ln ^{2} \sigma_{l}}\right)$.

$n_{l}(D)$ is the size distribution function of mode $l, D$ is the particle diameter, $N_{l}$ is the number concentration, $\sigma_{l}$ is the geometric standard deviation and $\bar{D}_{l}$ is the geometric median diameter of mode $l$.

For submicron particles five modes are used. Two modes represent secondary, internally mixed particles consisting of sulphate, ammonium, nitrate, secondary organic compounds, and water. One mode represents pure soot. Two more modes represent aged soot particles consisting of sulphate, ammonium, nitrate, organic compounds, water, and soot in an internal mixture. All modes are subject to intra- and intermodal coagulation. Furthermore, three modes, which represent sea salt particles, are used. Since only the very southern part of the model domain was affected by mineral dust particles during the investigated period, mineral dust particles are not 
considered in this study. The sources for the particulate mass are the binary nucleation of sulphuric acid and water, condensation of gases on the particles and, in case of soot and sea salt particles, the direct emissions. A detailed description of the emission inventories is given in Sect. 2.4. The nucleation rates are calculated using the parameterization of Kerminen and Wexler (1994).

A detailed description of the model is given in Vogel et al. (2009).

\subsection{CCN calculation}

COSMO-ART is capable of detailed simulations of the aerosol size distribution, the chemical composition and the mixing state of the aerosol. Hence, we can use all this information for the calculation of the $\mathrm{CCN}$.

We calculate the available $\mathrm{CCN}$ based on the classical Köhler theory (Köhler, 1936). For the representation of the internal chemical mixture of the particles we follow the approach of Hänel (1976). We assume ideal solutions, because the non-ideal behaviour of solution droplets depends on the droplet size. For each mode $l$ the minimum dry diameter $D_{l}^{*}$, which is a function of the chemical composition, is calculated for a specific maximum supersaturation $s$ :

$D_{l}^{*}=\left(\frac{4 A^{3}}{27 \bar{B}_{l} s^{2}}\right)^{1 / 3}, \quad \bar{B}_{l}=\frac{M_{\mathrm{w}} \sum_{i} v_{i} r_{i} \varepsilon_{i} / M_{i}}{\rho_{i} \sum_{i} r_{i} / \rho_{i}}, \quad A=\frac{4 \sigma_{\mathrm{w}} M_{\mathrm{w}}}{R T \rho_{\mathrm{w}}}$.

$\bar{B}_{l}$ is the mean hygroscopicity parameter for the chemical composition of the particles in mode $l, A$ is the curvature parameter, $\sigma_{\mathrm{w}}$ is the surface tension, $\rho_{\mathrm{w}}$ the density and $M_{\mathrm{w}}$ the molecular weight of water, $v_{i}$ is the dissociation factor, $\varepsilon_{i}$ the soluble fraction, $M_{i}$ the molecular weight, $\rho_{i}$ the density, $r_{i}$ the mass mixing ratio of component $i$ in mode $l, R$ is the universal gas constant and $T$ is the temperature.

Finally the integration of the size distribution of each mode $l$ and summation of all modes results in the number of available $\mathrm{CCN}$ :

$\operatorname{CCN}(s)=\sum_{l} \int_{D_{l}^{*}}^{\infty} n_{l}(D) d D$.

\subsection{Activation rate}

The main challenge in linking aerosol particles with clouds in a three dimensional model is the calculation of the activation rate of the particles, which depends on the maximum supersaturation that occurs during the formation of the cloud droplets.

For the activation of the aerosol particles the mechanistic parameterization of Abdul-Razzak and Ghan (2000) is used. Here, the maximum supersaturation $s_{\max }$ in an ascending air parcel is calculated on the basis of the aerosol properties and the updraft velocity. For this purpose, four dimensionless parameters were derived and determined by means of detailed parcel simulations. To account for size-dependent growth kinetics we are using an average modified diffusivity of water vapour (Fountoukis and Nenes, 2005).

In contrast to global models, mesoscale models with spatial resolutions of 2 to $20 \mathrm{~km}$ can simulate the location and the characteristics of larger individual cloud systems. But, the updraft velocities during cloud formation cannot be reproduced quantitatively by the simulated grid-scale vertical velocity $w$. This will cause a strong underestimation of updrafts in the model and will cause underpredictions of supersaturation, which result in too low cloud droplet number (CDN) concentrations. To consider the impact of subgridscale updrafts at the cloud base, we use the pragmatic approach of Lohmann et al. (1999) by adding an additional factor to $w$, which is proportional to the square root of the turbulent kinetic energy TKE. To include radiative cooling and heating and, thereby, the formation of fog in the activation parameterization, a pseudo updraft velocity is calculated and added to $w$ (Seinfeld and Pandis, 2006). Thus, the updraft $w_{\mathrm{cb}}$, which is used for the calculation of the supersaturation, becomes:

$w_{\mathrm{cb}}=w+0.7 \sqrt{\mathrm{TKE}}-\frac{c_{\mathrm{p}}}{g}\left(\frac{d T}{d t}\right)_{\mathrm{rad}}$,

where $g$ is the acceleration of gravity and $c_{\mathrm{p}}$ is the heat capacity at constant pressure.

Because the activation parameterization results only in a number of activated particles, one has to calculate the rate of the activation in the model. Most models (e.g., Lohmann et al., 2007; Storelvmo et al., 2006) calculate the activation rate by dividing the difference between the parameterized number of activated particles and the number of pre-existing cloud droplets by the time step interval. In global models, this can be justified by the coarse resolution in space and time. In a mesoscale model, the dimensions of the clouds and their different developing stages can be resolved in more detail; therefore, the activation rate has to be derived on the basis of the cloud dynamics.

The activation rate of the aerosol particles, respectively the nucleation rate of cloud droplets, is derived following Ghan and Abdul-Razzak (1997). Thereby, in-cloud activation of particles is not possible, and two cases are distinguished. Particles can get activated only in the case of a newly formed cloud or by vertical transport into the cloud base. For a "new" cloud the parameterized $\mathrm{CCN}\left(s_{\max }\right)$ concentration is used directly as the number of activated aerosols for this time step. In case of an "old" cloud, the advection and turbulent diffusion into the cloud are considered. The activation rate for an "old" cloud then becomes:

$\mathrm{ACT}=-\frac{\partial}{\partial z} \operatorname{CCN}_{\mathrm{cb}}\left(s_{\max }\right) w+\frac{\partial}{\partial z} K \frac{\partial}{\partial z} \operatorname{CCN}_{\mathrm{cb}}\left(s_{\max }\right)$,

where $z$ is the vertical coordinate, $\mathrm{CCN}_{\mathrm{cb}}\left(s_{\max }\right)$ is the parameterized number of $\mathrm{CCN}\left(s_{\max }\right)$ below the cloud, and $K$ is the turbulent diffusion coefficient. 
In this study activation scavenging of aerosol particles is not considered. Consequently, in-cloud aerosol and in-cloud processing of the aerosol particles are not considered.

\subsection{Cloud scheme}

The cloud scheme is an extended version of the one moment bulk scheme used for operational weather forecast with the COSMO model (Doms et al., 2005). The scheme includes prognostic equations for the mass mixing ratio of cloud water, rain water, cloud ice and snow. We expanded this scheme with a prognostic equation for the cloud droplet number concentration. For the representation of autoconversion, accretion, and self-collection of cloud drops, the twomoment parameterizations of Seifert and Beheng (2001) are used. The autoconversion rate is inversely proportional to the square of the number concentration of cloud droplets $\left(N_{\mathrm{c}}\right)$. For the cloud droplets a Gamma distribution function is assumed. The autoconversion parameterization relies on a solution of the stochastic collection equation and is well validated against simulations using spectral bin microphysics (Seifert et al., 2006b). The budget equations for the mixing ratio of cloud water $\left(x_{\mathrm{c}}\right)$ and the number concentration of cloud droplets $\left(N_{\mathrm{c}}\right)$ are:

$$
\begin{aligned}
& \frac{\partial}{\partial t} x_{\mathrm{c}}=\mathrm{ADV}_{m}+\mathrm{DIFF}_{m}+\mathrm{COND}_{m}-\mathrm{AU}_{m}-\mathrm{ACC}_{m} \\
& +\mathrm{MELT}_{m}-\mathrm{ICEP}_{m}, \\
& \frac{\partial}{\partial t} N_{\mathrm{c}}=\mathrm{ADV}_{N}+\mathrm{DIFF}_{N}+\mathrm{ACT}-\mathrm{AU}_{N}-\mathrm{ACC}_{N} \\
& -\mathrm{SC}_{N}+\mathrm{MELT}_{N}-\frac{\rho_{\mathrm{h}}}{\bar{m}_{\mathrm{c}}} \mathrm{ICEP}_{m},
\end{aligned}
$$

where $\mathrm{ADV}_{m}$ and $\mathrm{ADV}_{N}$ are the tendencies due to advection, $\mathrm{DIFF}_{m}$ and $\mathrm{DIFF}_{N}$ are the tendencies due to turbulent diffusion, $\mathrm{COND}_{m}$ is the tendency due to condensation of water, $\mathrm{AU}_{m}, \mathrm{AU}_{N}, \mathrm{ACC}_{m}, \mathrm{ACC}_{N}$, and $\mathrm{SC}_{N}$ are the tendencies due to the autoconversion, accretion, and self-collection, $\bar{m}_{\mathrm{c}}=x_{\mathrm{c}} N_{\mathrm{c}}^{-1} \rho_{\mathrm{h}}$ is the mean droplet mass and $\rho_{\mathrm{h}}$ is the density of humid air. MELT $_{m}$ and MELT $_{N}$ are the tendencies due to melting of cloud ice. Cloud ice crystals are assumed to melt instantaneously when the ambient temperature rises above $0{ }^{\circ} \mathrm{C}$ and the melting ice crystal number concentration is assumed to be the maximum of either $100 \mathrm{~m}^{-3}$ or $\rho_{\mathrm{h}} x_{i} / \bar{m}_{i}^{\max }$, where $x_{i}$ is the ice mass mixing ratio and $\bar{m}_{i}^{\max }=10^{-9} \mathrm{~kg}$ is the maximum mean ice crystal mass in the model (Doms et al., 2005). ICEP $_{m}$ is the tendency of cloud water mixing ratio due to microphysical processes with the ice phase. These are in detail the freezing of droplets, the riming and the shedding on snow. The homogeneous freezing of cloud droplets occurs at a temperature of $236.15 \mathrm{~K}$, where all cloud water is assumed to freeze instantaneously. The microphysical processes in the ice phase are calculated with the original one moment bulk approach of COSMO (Doms et al., 2005). The heterogeneous nucleation of cloud ice is possible for temperatures below $T=267.15 \mathrm{~K}$ and the inital ice crystal number concentration $N_{i}$ is based on an updated version of the classical Fletcher-formula (Fletcher, 1962)

$N_{i}(T)=N_{0}^{i} e^{0.2\left(T_{0}-T\right)}$,

where $N_{0}^{i}=100 \mathrm{~m}^{-3}$ and $T_{0}$ is the temperature at the freezing point $(273.15 \mathrm{~K})$. Heterogeneous nucleation of cloud ice requires water saturation for $T>248.15 \mathrm{~K}$ and ice saturation for lower temperatures. To calculate the initial ice mass mixing ratio an initial mean ice crystal mass of $10^{-12} \mathrm{~kg}$ is assumed (Doms et al., 2005).

For subgrid-scale convective clouds the Tiedtke scheme (Tiedtke, 1989) is used, which does not include explicit cloud microphysics.

\subsection{Emissions}

The anthropogenic emission data account for traffic emissions, emissions by large point sources, and area sources such as households and industrial areas and have an hourly resolution (Pregger et al., 2007). The data include emissions of the gases $\mathrm{SO}_{2}, \mathrm{CO}, \mathrm{NO}_{\mathrm{x}}, \mathrm{NH}_{3}, 32$ individual classes of VOC, and the direct emission of elemental carbon particles.

The emission of sea salt is calculated online as a function of the wind speed and the sea water temperature. For this a combination of three individual parameterizations for three individual size ranges is used (Lundgren, 2006).

The anthropogenic emissions of inorganic and organic compounds are prescribed with a temporal resolution of one hour, and the natural emissions are online calculated at each time step (Vogel et al., 2009).

\section{Results}

With the extended model version of COSMO-ART, the chain from emission of gases, gas phase chemistry, nucleation of particles, activation of the particles up to clouds and precipitation on the regional scale can be simulated. Due to this online coupling of gases, aerosol and clouds, different feedback mechanisms can be considered in the simulations. Clouds strongly modify the radiation in the atmosphere which has an impact on photochemistry and dynamics and therefore on the distribution of aerosol particles. This modifies the number of available $\mathrm{CCN}$ and, therefore, has an impact on the size distribution of the cloud droplets. As a result the autoconversion of droplets to rain can be altered, which can cause a change in precipitation and by release or absorption of latent heat in different layers, the dynamics can be influenced. The change in precipitation consequently alters the aerosol distribution by washout of particles. The change in dynamics can also change the emissions of sea salt, which can cause a strong change in the number of available $\mathrm{CCN}$ especially in clean marine air.

Figure 1 gives an overview of the feedback mechanisms which are treated in this application of COSMO-ART. 


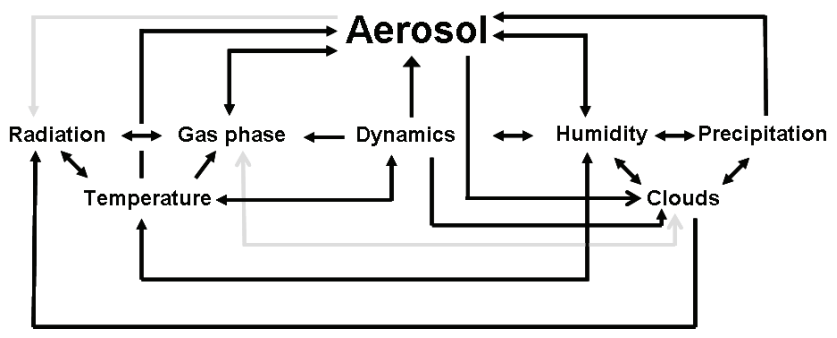

Fig. 1. Feedback mechanisms considered in COSMO-ART. Grey arrows indicate feedbacks that are neglected in this study.

The extended model system COSMO-ART is applied to investigate and quantify the interaction of aerosol particles, $\mathrm{CCN}$ and clouds on the regional scale. In this first application we addressed the following questions:

1. Are there systematic patterns in the distributions of aerosol number and mass concentration, $\mathrm{CCN}$ number concentration, and $\mathrm{CDN}$ concentration? Are there close links between them?

2. Is there a relation between $\mathrm{CCN}$, terrain slope, and cloud droplet number concentrations?

3. How are precipitation patterns altered when the interaction of aerosol particles and warm cloud processes are taken into account?

\subsection{Model setup}

A horizontal grid size of $0.125^{\circ}(\sim 14 \mathrm{~km})$ in both horizontal directions and 40 vertical levels up to a height of $20 \mathrm{~km}$ were used. The meteorological initial and boundary conditions are taken from the IFS model analyses of ECMWF. For the gaseous compounds and the aerosol particles, clean air conditions are prescribed. The analyses are used to update the meteorological boundary conditions every six hours. At the lateral boundaries a buffer zone is applied for all variables, according to the standard procedure of the COSMO model.

The simulation domain covers large parts of Europe and the Mediterranean Sea (Fig. 2). The simulation period is 1620 August 2005. The domain and period are identical to the high cloud cover case in Vogel et al. (2009) in which the direct radiation feedback of the aerosol particles has been investigated and a comprehensive comparison of the simulated aerosol distributions with COSMO-ART to observations has been carried out.

Until 18 August the domain is mainly influenced by a high pressure ridge over Europe. During the following days a high level trough approached Europe and caused a cyclogenesis over the Benelux. This yielded cloudy conditions, precipitation, and westerly winds for large parts of Europe. During the last two days of the period a frontal system passed
Table 1. Simulation description.

\begin{tabular}{lcll}
\hline Simulation & Period & Aerosol & Initial Data \\
\hline A & 16-20 August 2005 & Simulated, 8 Modes & ECMWF \\
B & 19-20 August 2005 & Constant, homogenous & Simulation A \\
\hline
\end{tabular}

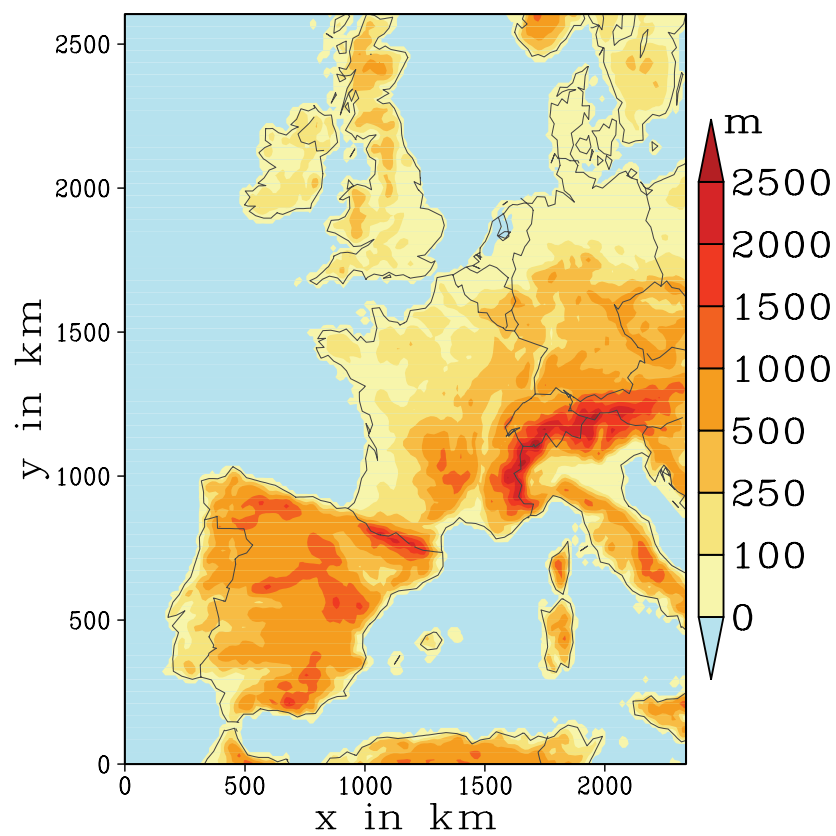

Fig. 2. Terrain height within the model domain.

France and Germany. This caused an enhanced development of clouds in the frontal area and a change in air mass from warm continental to cool maritime air.

Two simulations were performed. In the simulation A the whole period from 16-20 August 2005 was simulated including all feedback processes described in Sect. 2. As we want to focus on the aerosol cloud interaction in this study, the direct radiation feedback of the aerosol particles with the radiation was switched off. Therefore, all feedbacks shown in this study are caused by the impact of the aerosol particles on the cloud microphysics. The first day was used to spin up the model and build up the aerosol concentration. For the analysis of the distribution of $\mathrm{CCN}$ and of the cloud properties the 18-20 August period was used. Simulation B was performed to quantify the impact of changes in aerosol concentration on cloud properties and precipitation. This simulation covers only the last two days of the period, where most of the precipitation occurred. The initial values for simulation B were taken from simulation A at 19 August, 00:00 UTC. In contrast to simulation A, a fixed aerosol concentration was prescribed in simulation $\mathrm{B}$ for the whole simulation domain (Table 1). The prescribed aerosol concentration is identical to the conditions at a single grid point in South-West Germany 


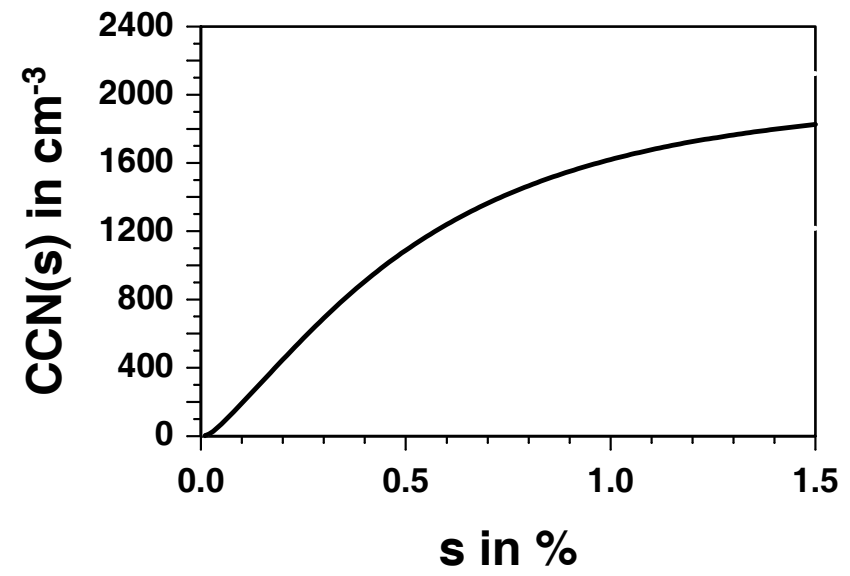

Fig. 3. CCN spectrum of the prescribed aerosol in simulation B.

at 19 August, 09:00 UTC, which represents approximately the average aerosol conditions during the simulation period. These values were kept constant and were used at all grid points in simulation B. The corresponding $\mathrm{CCN}$ spectrum of the prescribed aerosol concentration is depicted in Fig. 3.

\subsection{Distribution of aerosols, cloud condensation nuclei, and cloud droplet number}

Figure 4a shows the total number concentration of the simulated aerosol averaged over the period 18-20 August and over the height interval 0 to $1500 \mathrm{~m}$. The highest number concentrations are found above Spain. Clean air is advected over areas with high emissions, which leads to the formation of new particles with small diameters. High particle number concentrations are also simulated above SouthGermany. The corresponding distribution of the simulated $\mathrm{CCN}(0.1 \%)$ number concentrations for simulation $\mathrm{A}$ are given in Fig. 4b. Above the Atlantic the CCN number concentrations are below $50 \mathrm{~cm}^{-3}$. It is evident that the spatial patterns of aerosol number concentrations and of $\mathrm{CCN}$ $(0.1 \%)$ are quite different. High $\mathrm{CCN}$ number concentrations on the order of $600 \mathrm{~cm}^{-3}$ are simulated in the southern part of Germany and in the northern part of the Po Valley. Comparing Fig. $4 \mathrm{a}$ and $\mathrm{b}$ shows that there is no obvious correlation between total aerosol number concentration and $\mathrm{CCN}$ $(0.1 \%)$ number concentration. We found the same for the aerosol mass concentration and CCN $(0.1 \%)$ number concentration. For example, over the ocean total aerosol mass concentration can be very high due to large sea salt particles but the $\mathrm{CCN}(0.1 \%)$ number concentration is very low. We also calculated the $\mathrm{CCN}$ at other supersaturations and found that the pattern of the $\mathrm{CCN}$ strongly depends on the supersaturation. This shows that the distribution of CCN strongly depends on the size distributions and the chemical compositions of the aerosol particles, which determine the shapes of the CCN spectra and, therefore, the distribution of CCN at different supersaturations.

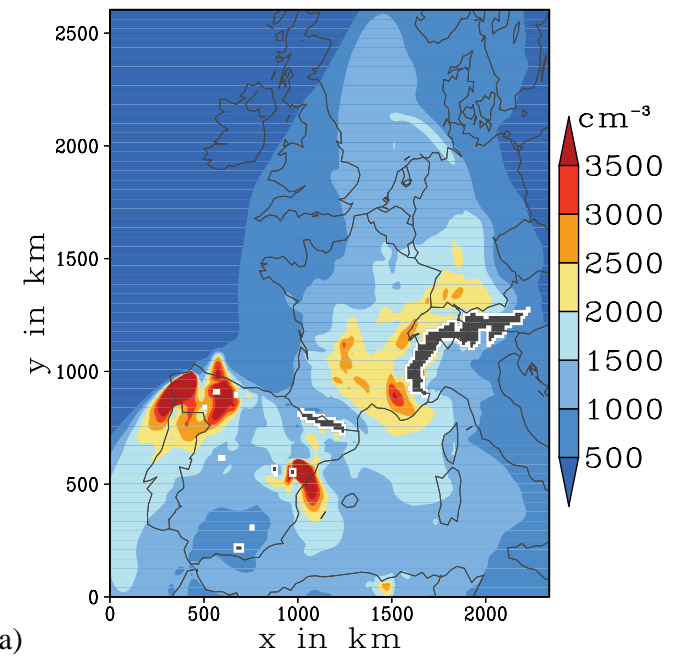

(a)

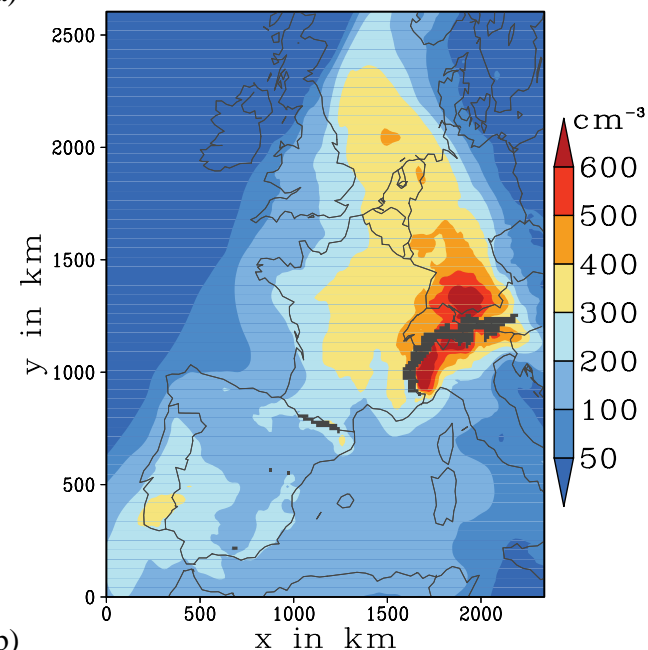

(b)

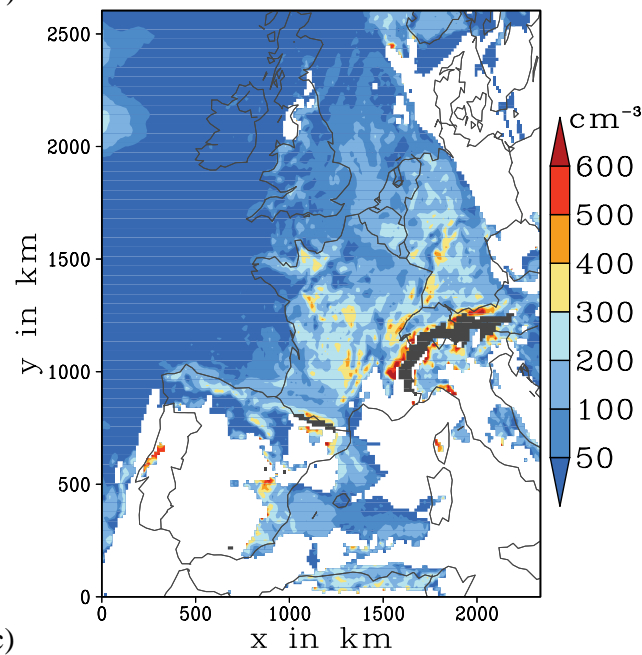

Fig. 4. Simulated spatial distributions (Simulation A) of (a) average aerosol number concentration, (b) average $\mathrm{CCN}(0.1 \%)$ number concentration and (c) average $\mathrm{CDN}$ concentration for the height interval 0 to $1500 \mathrm{~m}$ a.s.l. and the time period 18-20 August 2005. 
Figure $4 \mathrm{c}$ shows the corresponding simulated CDN concentrations. The average $\mathrm{CDN}$ concentrations reach their highest values, on the order of $400 \mathrm{~cm}^{-3}$, above France, Benelux, and Germany. Above the Atlantic CDN concentrations are below $50 \mathrm{~cm}^{-3}$. The pattern of the $\mathrm{CDN}$ concentration shows a very patchy distribution. The highest concentrations are found in the vicinity of mountainous regions. We investigated this in more details.

\subsection{Terrain slope, condensation nuclei and cloud droplet number}

The number of droplets inside a cloud depends on a variety of processes. On the one hand, the vertical velocity and the aerosol population determine the number of activated particles and, therefore, the initial CDN. On the other hand the microphysical processes inside the cloud change the cloud droplet spectra during the development of the cloud in time. With regional scale simulations it is possible to consider the complex topography which has local and systematic impact on the state of the atmosphere and therefore on, for instance, the vertical wind field. Based on our results we checked if there is a relation between terrain slope, $\mathrm{CCN}$, and CDN. We use a very basic approach to quantify the terrain slope TS at a certain grid point by

$$
\begin{aligned}
& \operatorname{TS}(i, j)=\frac{1}{4 \Delta x}(|h(i, j)-h(i-1, j)|+|h(i, j)-h(i+1, j)| \\
& +|h(i, j)-h(i, j-1)|+|h(i, j)-h(i, j+1)|),
\end{aligned}
$$

in which $h$ is the terrain height and $\Delta x$ is the horizontal grid size.

The dependency of average CDN on CCN $(0.1 \%)$ and TS are given in Fig. 5a. The figure shows that the highest CDN concentrations are found in areas where the terrain slope is high.

Complex topography is able to modify the vertical wind field in the atmosphere. With the performed regional scale simulations we are able to resolve the mesoscale impact of the terrain slope on the vertical wind velocities. The Distribution functions $n_{\mathrm{w}}$ of the simulated vertically averaged grid-scale vertical velocities inside the clouds are shown in Fig. 5b. When TS is increasing, the mean grid-scale vertical velocity within the clouds is increasing.

In flat areas with TS lower than 0.01, the negative and the positive vertical velocities occur with equal frequency. $75 \%$ of the vertical velocities within the clouds are greater than zero, when TS is larger than 0.01. This implies that in mountainous areas clouds are on average mainly in a development stage in which new particles can get activated. This explains the average higher CDN concentrations in the mountainous areas. Reutter et al. (2009) defined aerosol- and updraftlimited regimes of cloud droplet formation. They found that for a high ratio of updraft velocity and aerosol number concentration the $\mathrm{CDN}$ concentration is very sensitive to changes in aerosol number concentration, where for low ratios the

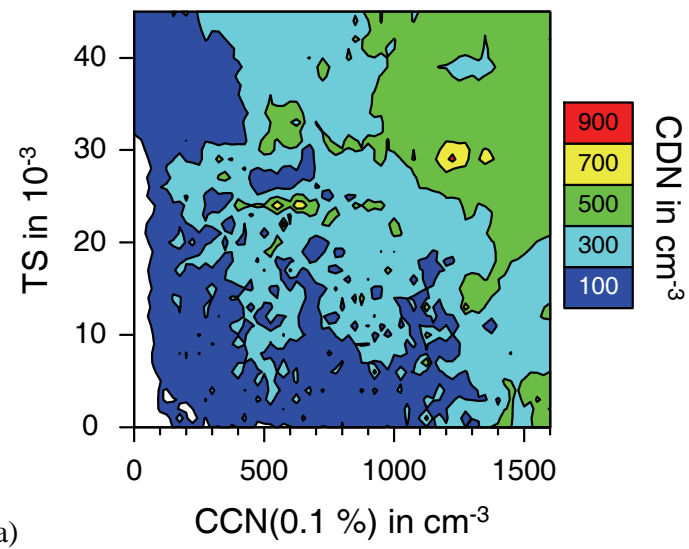

(a)

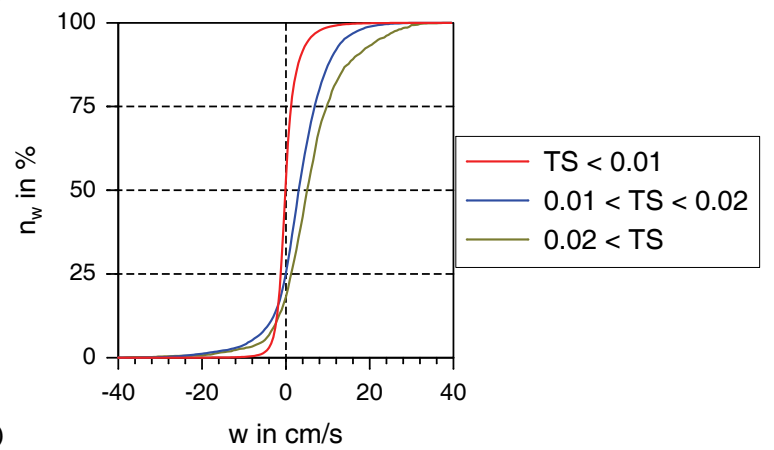

Fig. 5. (a) Dependence of CDN concentrations on terrain slope parameter TS and CCN $(0.1 \%)$ concentration for 18-20 August 2005 (b) Cumulative percentage contribution $n_{\mathrm{W}}$ of the grid-scale incloud vertical velocity for different values of TS for 18-20 August 2005. CDN and CCN concentrations as well as the in-cloud vertical velocity are vertical averages for 0 to $1500 \mathrm{~m}$ a.s.l. (Simulation A).

CDN is relatively insensitive to changes in the aerosol number concentration.

We found that similar regimes can be separated in terms of average $\mathrm{CDN}, \mathrm{CCN}$, and TS. In mountainous areas the $\mathrm{CCN}$ are the dominant factor, whereas in flat areas the average CDN is less sensitive to changes in $\mathrm{CCN}$. This can be explained by the dependency of aerosol activation on updraft velocity and aerosol number.

To simulate the interaction of aerosol particles with clouds in modern global climate models, the subgrid-scale vertical velocities are crucial for the calculation of aerosol activation. Because the spatial resolution is too coarse to resolve the updrafts during cloud development, parameterizations have to be used. Many climate models integrate the activation parameterization for a given probability density function (PDF) of the vertical velocity to calculate the aerosol activation in one grid box. For this approach, the PDF of the subgrid-scale vertical velocity must be known. A common approach is to use the grid-scale vertical velocity as the centre of the PDF and to determine the width corresponding to the turbulence e.g., the vertical eddy diffusivity or the turbulent kinetic energy (e.g., Storelvmo et al., 2006). 
From our findings we suggest a parameterization of the PDF of subgrid-scale vertical velocities in climate models which also takes the effect of subgrid-scale terrain slope (TS) into account. A first pragmatic approach is to determine the centre of the PDF $w_{\text {PDF }}$ as a linear function of the grid averaged subgrid-scale $\mathrm{TS}, \overline{\mathrm{TS}}$,

$w_{\mathrm{PDF}}=a \cdot \overline{\mathrm{TS}}$,

where $a \approx 2.8 \mathrm{~m} \mathrm{~s}^{-1}$ is a rough estimate, based on the data depicted in Fig. 5b. An improved formulation of the parameterization, based on a statistical analysis of model results that cover a period of several years with a high spatial resolution, will be presented in a future study. Such a parameterization results in more realistic cloud droplet numbers in mountainous regions. For climate models without the representation of aerosols, a pragmatic parameterization of $\mathrm{CDN}$ as a function of TS could be developed.

\subsection{Aerosol number concentrations in the vicinity of clouds}

In several measurement studies (Weigelt et al., 2009; Twohy et al., 2002; Keil and Wendisch, 2001; Hegg et al., 1990) high number concentrations of aerosol particles, respectively $\mathrm{CCN}$, were found in the vicinity of clouds. Radke and Hobbs (1990) suggested that the vertical transport of precursor gases, the enhanced photolysis above the cloud and the high humidity in these regions can cause nucleation events and as a consequence high number concentrations of aerosol particles close to the clouds. To see if this process is important in our simulations, we first identified where the major nucleation events occur. We checked the extent to which COSMO-ART is able to reproduce this feature.

Figure 6a shows the time evolution of the profile of the horizontally averaged difference in the total aerosol number concentration of cloudy to cloud free grid points. The difference is mainly positive with high values in the free troposphere during midday. In Fig. 6b, the time evolution of the profile of horizontally averaged nucleation is shown. The criterion for a nucleation event is a change of more than $10^{4}$ particles $\mathrm{h}^{-1} \mathrm{~cm}^{-3}$ in the smallest aerosol mode. In our simulations the nucleation of particles occurs in the late morning in the free troposphere. The nucleation is strongest at 19 August, with a maximum at an altitude of approximately $5000 \mathrm{~m}$ a.s.l. The occurrence of the nucleation events is consistent with the maximum differences in the total aerosol number. The higher aerosol number in the vicinity of clouds can therefore be explained by more effective nucleation close to the clouds. This supports the findings of the aforementioned studies.

Finally, this has an impact on the number of available CCN in areas where clouds develop. Figure 7 shows the time evolution of the profile of the ratio of horizontally averaged CCN $(0.1 \%)$ at grid cells containing cloud water and of horizontally averaged $\mathrm{CCN}(0.1 \%)$ at cloud free grid cells. Below

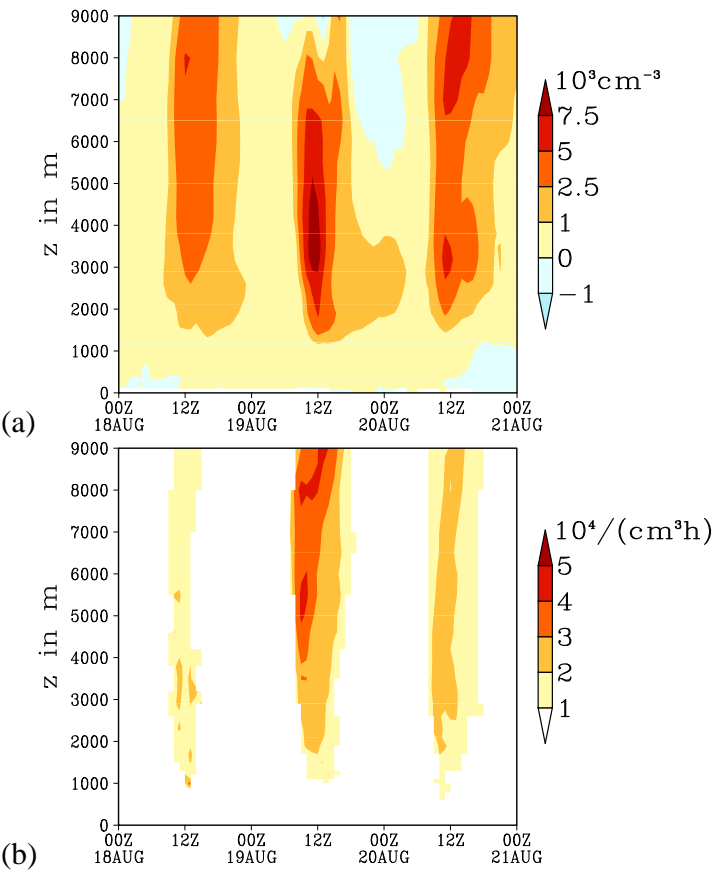

Fig. 6. (a) Time evolution of the profile of the difference in the horizontally averaged total aerosol number concentration of cloudy to cloud free grid points, (b) time evolution of the profile of the horizontally averaged nucleation rate.

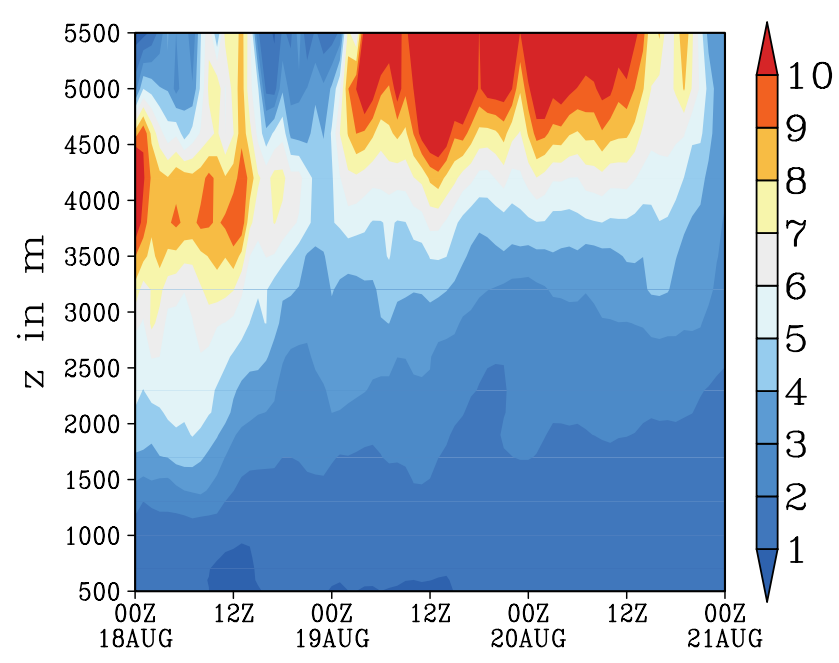

Fig. 7. Time evolution of the profile of the ratio of horizontally averaged $\mathrm{CCN}(0.1 \%)$ concentrations at grid cells containing cloud water and at cloud free grid cells.

$1000 \mathrm{~m}$ a.s.l. the ratio is close to 1 and then increases monotonically up to a ratio of 10 in $5000 \mathrm{~m}$ a.s.l. This ratio is nearly constant during the passage of the front system from 19-20 August. In the free troposphere, the simulated number concentration of $\mathrm{CCN}(0.1 \%)$ is much higher in areas where the clouds develop than in the cloud free surroundings. 
Despite the fact that the enhanced nucleation plays a crucial role here, vertical transport of particles is also important. Flossmann (1998) showed that in a medium-sized convective cloud up to $70 \%$ of the particulate mass can be transported into the free troposphere and can cause an accumulation of particles above the cloud.

\subsection{Aerosols, clouds, and precipitation}

The net impact of aerosol on clouds and precipitation can hardly be quantified in general because of the regimedependent complex interactions (Stevens and Feingold, 2009). Besides the direct impact of aerosol on cloud microphysics due to changes in $\mathrm{CCN}$ number and therefore changes in droplet size, the dynamics and the atmospheric water cycle play an important role for the development of the clouds and the formation of precipitation (Sandu et al., 2008, 2009; Khain et al., 2008). Stevens and Feingold (2009) pointed out that interactions on different spatial and temporal scales can buffer the impact of aerosol changes to some extent. How efficient these buffering processes are is not yet known.

With simulations of several days for a large model domain, we are able to treat the direct microphysical response of the cloud to aerosol changes and also the resulting macrophysical feedbacks on dynamics and on the water cycle. Therefore, we are able to investigate in which way aerosol alters the net response of cloud properties and precipitation.

Introducing a perturbation in regional-scale atmospheric simulations, due to new physical processes or artificially, will in general result in a perturbed precipitation distribution due to e.g., spatial shifts in the location of locally isolated cloud systems after several simulation days. For this reason we will focus on a short simulation period of two days from 1920 August 2005 for the analysis of the aerosol precipitation interaction.

In Fig. 8a the difference of the mean CDN concentration between simulation A and B are shown for the period of 1920 August 2005. The simulated aerosol particles in simulation A cause lower CDN over the ocean and higher CDN over the continent and the Northern Sea compared to the prescribed aerosol in simulation B. The changes in mean CDN are directly related to the different availability of $\mathrm{CCN}$ in the two simulations.

The difference in $\mathrm{CDN}$ is reflected in the difference of the mean droplet size for most parts of the model domain, but there are also local regions, e.g. some parts over Western Germany, where the mean cloud droplet size is bigger despite the higher mean CDN (Fig. 8b). Dynamic feedbacks and, therefore, changes in the condensation overcome the initial impact of the aerosol on the microphysics in these areas.

Figure 9a shows the total accumulated precipitation of run A for the 19-20 August 2005. Over the Atlantic Ocean weak precipitation was produced by warm stratocumulus clouds. The precipitation amount did not exceed $5 \mathrm{~mm}$ in this area

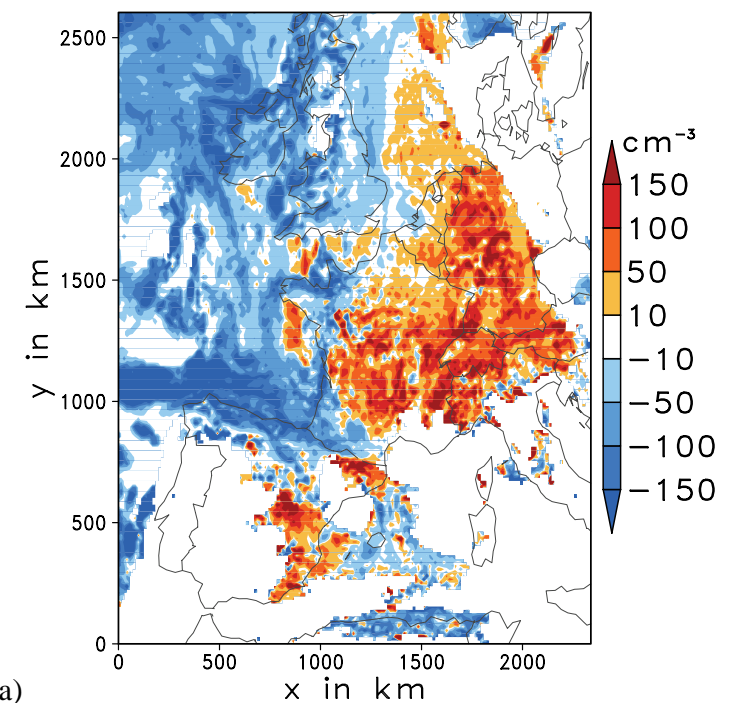

(a)

(b)

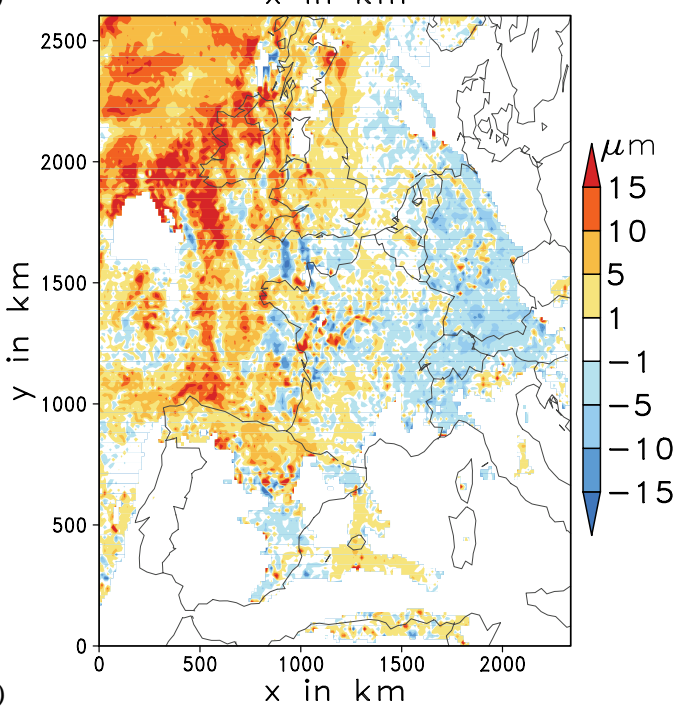

Fig. 8. Difference in the (a) average CDN concentration and (b) the average mean cloud droplet diameter between simulation $\mathrm{A}$ and $\mathrm{B}$ for 0 to $1500 \mathrm{~m}$ a.s.1. and 19-20 August 2005.

during this period. The highest precipitation amounts with values up to more than $30 \mathrm{~mm}$ occurred in the region of the Alps, the southern part of Germany, in France, and around the depression over the Northern Sea. The precipitation in these areas is produced mainly by mixed phase clouds.

The difference of the total accumulated grid-scale precipitation of A and B are depicted in Fig. 9b. Over the ocean the lower $\mathrm{CCN}$ number and, consequently, the bigger mean cloud droplet size caused an increase of the precipitation amount in the order of a few $\mathrm{mm}$ for the whole area. This is directly related to the more efficient formation of warm precipitation in the shallow stratiform clouds due to the lower $\mathrm{CCN}$ number concentration.

In case of the mixed phase cloud system, the impact of the aerosol changes on the precipitation is quite different. 


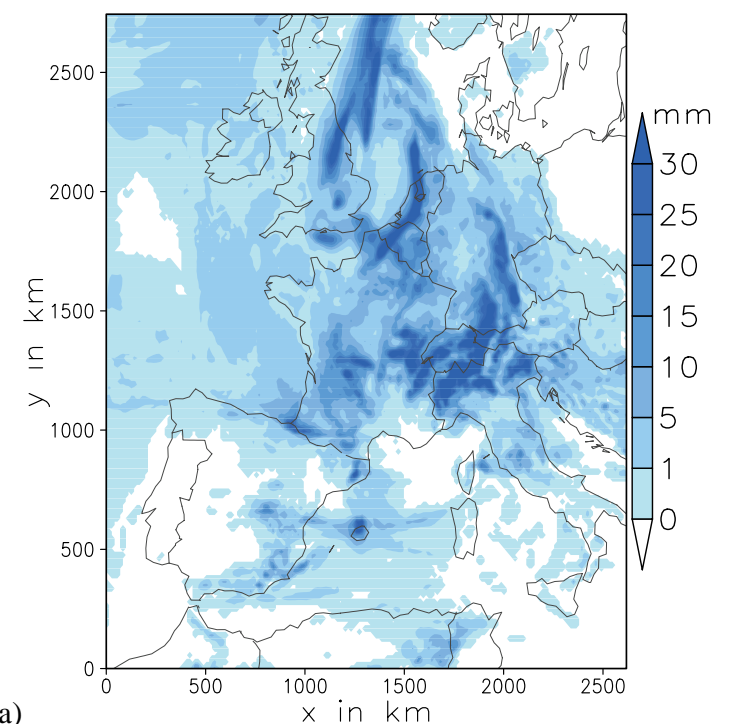

(a)

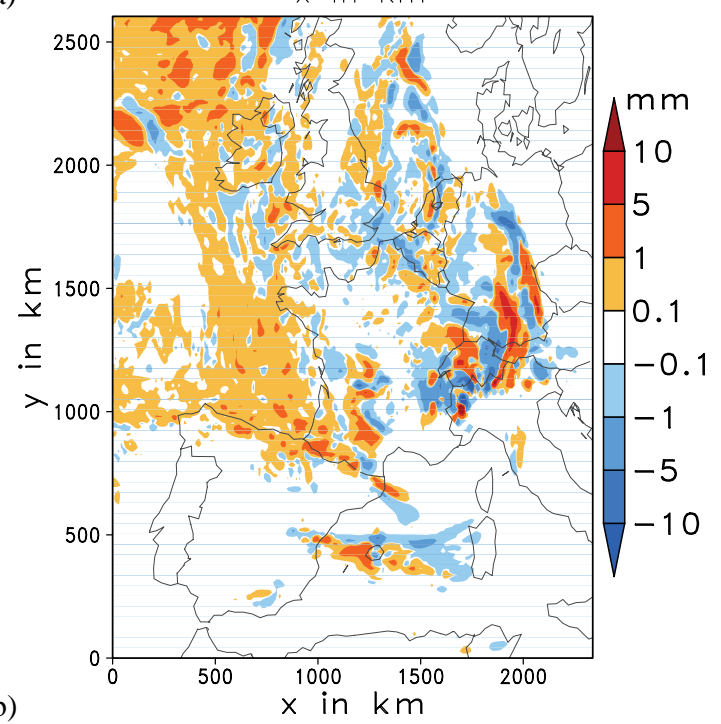

Fig. 9. (a) Accumulated precipitation amount in simulation A for 19-20 August 2005, (b) difference of the accumulated precipitation amount between simulation A and B for 19-20 August 2005.

Whereas the location of the precipitation events is almost identical in both simulations, the total amount of the precipitation shows an alternation of increases and decreases. This is due to temporal and spatial shifts of the precipitation produced by the individual moving cloud systems.

In the areas with mixed phase clouds and higher precipitation amounts, the clouds have, on average, more condensate and higher updrafts inside the clouds in simulation $\mathrm{A}$ in which the $\mathrm{CCN}$ number is higher. Therefore, the impact on the precipitation can be related mainly to dynamical effects, which can be initially caused by the changes in the aerosol concentration (Seifert and Beheng, 2006a). But previous and surrounding clouds can also affect the dynamics in several ways. Because of the complex non-linear interactions, the individual processes can hardly be separated.
For the quantification of the impact of the $\mathrm{CCN}$ on the precipitation, the precipitation susceptibility $\beta$ can be used (Sorooshian et al., 2009). $\beta$ is a measure of the response of the precipitation to changes in $\mathrm{CDN}$ or CCN. Here $\beta$ is calculated as a function of the vertical mean $\mathrm{CCN}(0.1 \%)$ for the model layer 4 to 15 which corresponds to approximately 300 to $2000 \mathrm{~m}$ a.s.l. at a certain point of time, $\overline{\mathrm{CCN}}$, and the rain amount of the following hour $R_{1 \mathrm{~h}}$. Precipitation events with less than $0.01 \mathrm{~mm}$ precipitation per hour are neglected.

$\beta=-\frac{\Delta \log \left(R_{1 \mathrm{~h}}\right)}{\Delta \log (\overline{\mathrm{CCN}})}$

$\beta$ is usually used for warm clouds, where positive values indicate their typical behaviour with more $\mathrm{CCN}$ cause less rain and negative values indicate more $\mathrm{CCN}$ cause more rain. Negative values of $\beta$ can only be caused by additional processes and feedbacks besides the direct microphysical impact of the CCN number concentration on droplet number concentration and on the coagulation of cloud droplets, respectively. In this study $\beta$ is applied for warm and mixed phase clouds. In contrast to other studies, which use one representative time during the development of a specific cloud, $\beta$ is calculated for each hour and for the whole simulation domain and, therefore, covers different development stages of clouds. The advantage of this is that not only the first impact of the aerosol on the precipitation but also the ongoing feedbacks during the further cloud development are covered. Aerosol can, at first, change the precipitation in the early development of the cloud by modifying the autoconversion which will result in a positive $\beta$. This process can then cause a feedback with the ice phase of the cloud causing a negative $\beta$, and then afterwards, due to a change in condensate in the cloud, $\beta$ can change its sign once again. A distribution of $\beta$, termed $n_{\beta}$, was calculated for the whole model domain and the last two days of the simulation period for about 110000 grid points (Fig. 10). The peak of $n_{\beta}$ is at a value of zero. The distribution shows that it is hard to estimate a mean value of $\beta$, for example for climate purposes, because both positive and negative $\beta$ occur almost in the same amount. Moreover, what can be seen by this single simulation, which covers different cloud types and their development over several days, is that there is a slight skewness of $n_{\beta}$ to positive values of $\beta$. This results in an overall mean $\beta$ of 0.23 for this simulation.

Sorooshian et al. $(2009,2010)$ separated different cloud regimes by correlating $\beta$ to the cloud liquid water path LWP for cloud parcel and LES simulations and satellite measurements. They found that $\beta$ increases with LWP till approximately $0.7-1 \mathrm{~kg} \mathrm{~m}^{-2}$ and then decreases again. In Fig. 11a, $\beta$ is shown as a function of cloud water path for our simulation. The mean $\beta$ increases with increasing cloud water path until $0.5 \mathrm{~kg} \mathrm{~m}^{-2}$ and then stays approximately constant at a value of 0.4 .

To find the LWP for which the impact of CCN on the precipitation is most significant in our simulations independent of the sign of $\beta$, we calculated the absolute value $|\beta|$ of $\beta$ 


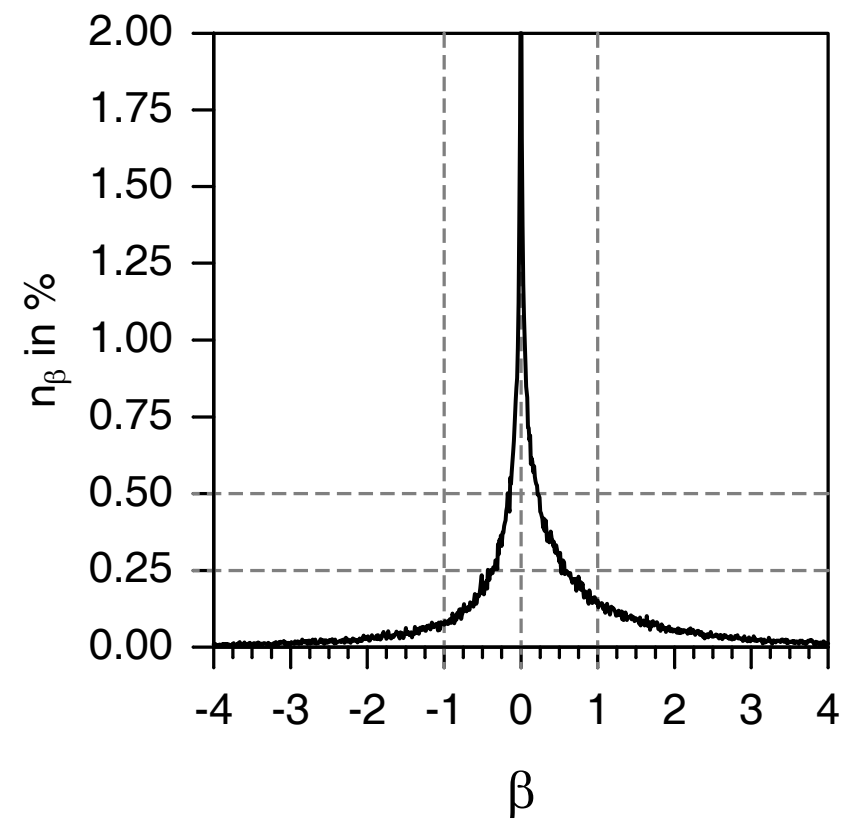

Fig. 10. Simulated relative distribution $n_{\beta}$ of $\beta$ for intervals of $\Delta \beta=0.01$ for 19-20 August 2005 .

for all points with an hourly precipitation amount greater than $0.2 \mathrm{~mm}$. In Fig. $11 \mathrm{~b},|\beta|$ is depicted as a function of cloud water path. It is increasing up to a value of 1 at LWP $=0.85$ and then decreasing for larger LWP. This result is in agreement with the results found by Sorooshian et al. $(2009,2010)$.

\section{Summary and conclusions}

We have extended the model system COSMO-ART to study the mesoscale processes related with aerosol, $\mathrm{CCN}$ and their interaction with warm cloud microphysics. With this model we are able to simulate the gases, aerosols and clouds with a comparable level of complexity and to investigate their interactions on the regional scale.

The model system was applied for Europe for a period in August 2005. We found that for the simulation of the $\mathrm{CCN}$ distribution, the treatment of aerosol size distribution and chemical composition is necessary and cannot be replaced by correlation of $\mathrm{CCN}$ with just the aerosol number or mass concentration.

We discovered that the mean $\mathrm{CDN}$ is dependent on the structure of the terrain and we presented a terrain slope parameter TS to classify this dependency. The dependency of CDN on the TS could be explained by the different PDF of in-cloud updrafts for different TS. We propose to use this relationship to parameterize the PDF of subgrid-scale cloud updraft velocity in climate models or directly for mean CDN for climate models in which no aerosol information is available.

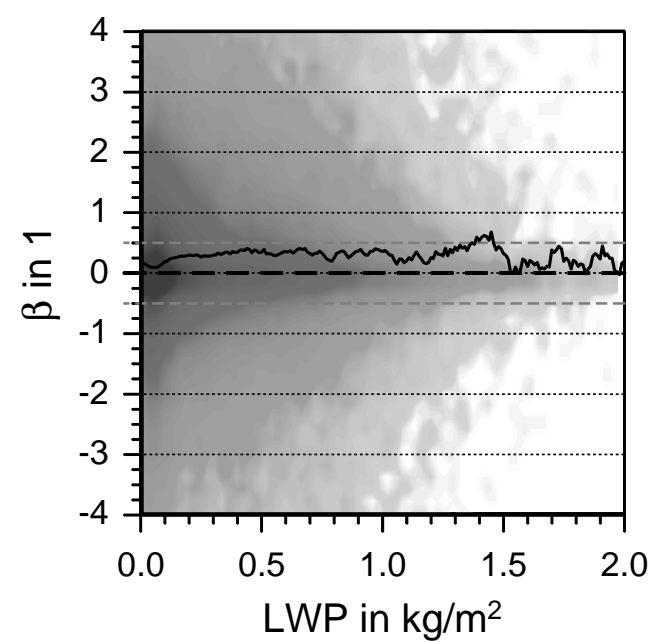

(a)

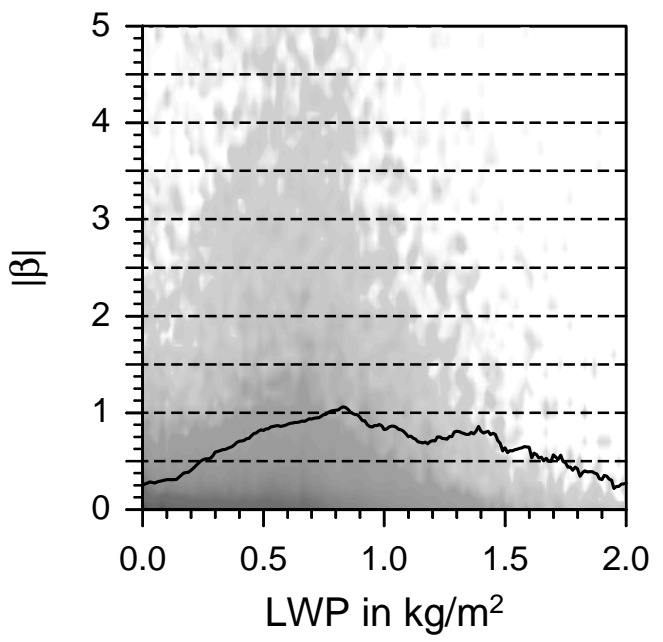

Fig. 11. (a) Simulated precipitation susceptibility $\beta$ as a function of cloud liquid water path LWP for all grid points for 19-20 August 2005 and (b) $|\beta|$ for all grid points with more than $0.2 \mathrm{~mm}$ per hour for the same period. Shadings show the joint histogram for the available precipitation data. Dark colors indicate a high density of data points.

The simulations showed big differences in aerosol number concentration in high altitudes during the late morning as well as a strong enhancement of CCN with increasing altitude in cloudy areas in comparison to cloud free areas. We showed that the nucleation of secondary particles is strongly enhanced above the clouds. This is caused by a more effective photochemistry, humid conditions, and the strong vertical transport of precursor gases in the cloudy areas. The simulations show that the distribution of $\mathrm{CCN}$ and clouds are strongly correlated with each other. Therefore, the treatment of complex photochemistry is crucial in atmospheric models to simulate the distribution of $\mathrm{CCN}$.

We calculated the changes of cloud properties and precipitation for prescribing a fixed aerosol distribution. The changes in the aerosol and the changes of CDN and mean 
droplet radii showed a clear correlation with more droplets and smaller radii in areas with more available $\mathrm{CCN}$. For precipitation the changes showed different behaviours with a slightly enhanced precipitation in the maritime stratus because of less CCN and spatial and temporal shifts in the precipitation over the continent where mixed phase clouds are dominant. To quantify the impact of the aerosol on the precipitation, we calculated the precipitation susceptibility $\beta$ for each time step and for the whole model domain. The distribution function of the susceptibility showed that both positive and negative values occur almost with equal frequency, but that the distribution has a slight skewness to positive values and a mean $\beta$ of 0.23 . In our simulations clouds with a liquid water path LWP of approximately $0.85 \mathrm{~kg} \mathrm{~m}^{-2}$ are most susceptible to aerosol changes with a absolute $\beta$ of 1 and the mean $\beta$ for LWP between $0.5 \mathrm{~kg} \mathrm{~m}^{-2}$ and $1 \mathrm{~kg} \mathrm{~m}^{-2}$ is approximately 0.4 .

Acknowledgements. We are grateful to A. Seifert for his support and valuable discussions concerning the cloud parameterizations.

Edited by: E. Vignati

\section{References}

Abdul-Razzak, H. and Ghan, S. J.: A parameterization of aerosol activation, 2. multiple aerosol types, J. Geophys. Res., 105, 6837-6844, 2000.

Cheng, C.-T., Wang, W.-C., and Chen, J.-P.: Simulation of the effects of increasing cloud condensation nuclei on mixed-phase clouds and precipitation of a front system, Atmos. Res., 96, 461476, 2010.

Doms, G., Förstner, J., Heise, E., Herzog, H.-J., Raschendorfer, M., Schrodin, R., Reinhardt, T., and Vogel, G.: A Description of the Nonhydrostatic Regional Model LM, Part II: Physical Parameterization, Deutscher Wetterdienst, Offenbach, 2005.

Fletcher, N. H.: The Physics of Rainclouds. Cambridge University Press, Cambridge, UK, New York, NY, USA, 1962.

Flossmann, A. I.: Interaction of aerosol particles and clouds, J. Atmos. Sci., 55, 879-887, 1998.

Forster, P., Ramaswamy, V., Artaxo, P., Berntsen, T., Betts, R., Fahey, D. W., Haywood, J., Lean, J., Lowe, D. C., Myhre, G., Nganga, J., Prinn, R., Raga, G., Schulz, M., and Van Dorland, R.: Changes in atmospheric constituents and in radiative forcing, in: Climate Change 2007: The Physical Science Basis. Contribution of Working Group I to the Fourth Assessment Report of the Intergovernmental Panel on Climate Change, edited by: Solomon, S., Qin, D., Manning, M., Chen, Z., Marquis, M., Averyt, K. B., Tignor, M., and Miller, H. L., Cambridge University Press, Cambridge, UK, New York, NY, USA, 2007.

Fountoukis, C. and Nenes, A.: Continued development of a cloud droplet formation parameterization for global climate models, J. Geophys. Res., 110, D11212, doi:10.1029/2004JD005591, 2005.

Ghan, S. and Abdul-Razzak, H.: Prediction of cloud droplet number in a general circulation model, J. Geophys. Res., 102, 2177721794, 1997.
Guohui, L., Wang, Y., Lee, K.-H., Diao, Y., and Zhang, R.: Impacts of aerosols on the development and precipitation of a mesoscale squall line, J. Geophys. Res., 114, 1-18, 2009.

Hänel, G.: The properties of atmospheric aerosol particles as functions of the relative humidity at thermodynamic equilibrium with the surrounding moist air, Adv. Geophys., 19, 73-188, 1976.

Hegg, D. A., Radke, L. F., and Hobbs, P. V.: Particle production associated with marine clouds, J. Geophys. Res., 95, 13917-13926, 1990.

Ivanova, I. T. and Leighton, H. G.: Aerosol-cloud interactions in a mesoscale model. Part I: Sensitivity to activation and collisioncoalescence, J. Atmos. Sci., 65, 289-307, 2008.

Keil, A. and Wendisch, M.: Bursts of Aitken mode and ultrafine particles observed at the top of continental boundary layer clouds, J. Aerosol Sci., 32, 649-660, 2001.

Kerminen, V.-M. and Wexler, A. S.: Post-fog nucleation of $\mathrm{H}_{2} \mathrm{SO}_{4}-$ $\mathrm{H}_{2} \mathrm{O}$ particles in smog, Atmos. Environ., 28, 2399-2406, 1994.

Khain, A. P.: Notes on state-of-the-art investigations of aerosol effects on precipitation: a critical review, Environ. Res. Lett., 4, 015004, doi:10.1088/1748-9326/4/1/015004, 2009.

Khain, A. P., Benmoshe, N., and Pokrovsky, A.: Factors determining the impact of aerosols on surface precipitation from clouds: an attempt at classification, J. Atmos. Sci., 65, 1721-1748, 2008.

Köhler, H.: The nucleus in and the growth of hygroscopic droplets, T. Faraday Soc., 32, 1152-1161, 1936.

Levin, Z. and Cotton, W. R.: Aerosol pollution impact on precipitation: a scientific review, Springer, Dordrecht, 2009.

Lohmann, U., Feichter, J., Chuang, C. C., and Penner, J. E.: Predicting the number of cloud droplets in the ECHAM GCM, J. Geophys. Res., 104, 9169-9198, 1999.

Lohmann, U., Stier, P., Hoose, C., Ferrachat, S., Kloster, S., Roeckner, E., and Zhang, J.: Cloud microphysics and aerosol indirect effects in the global climate model ECHAM5-HAM, Atmos. Chem. Phys., 7, 3425-3446, doi:10.5194/acp-7-3425-2007, 2007.

Lundgren, K.: Numerical Simulation of the Spatial and Temporal Distribution of Sea Salt Particles on the Regional Scale, M.Sc. thesis, Department of Meteorology Stockholm University, Stockholm, Sweden, 2006.

Merikanto, J., Spracklen, D. V., Mann, G. W., Pickering, S. J., and Carslaw, K. S.: Impact of nucleation on global CCN, Atmos. Chem. Phys., 9, 8601-8616, doi:10.5194/acp-9-8601-2009, 2009.

Muhlbauer, A. and Lohmann, U.: Sensitivity studies of aerosolcloud interactions in mixed-phase orographic precipitation, J. Atmos. Sci., 66, 2517-2538, 2009.

Ntelekos, A. N., Smith, J. A., Donner, L., Fast, J. D. W., Gustafson, W. I. Jr., Chapman, E. G., and Krajewski, W. F.: The effects of aerosols on intense convective precipitation in the Northeastern United States, Q. J. Roy. Meteor. Soc., 135, 13671391, 2009.

Pregger, T., Thiruchittampalam, B., and Friedrich, R.: Ermittlung von Emissionsdaten zur Untersuchung der Klimawirksamkeit von Rußpartikeln in Baden-Württemberg, Final Report, IER Universität Stuttgart, Stuttgart, 2007.

Pringle, K. J., Carslaw, K. S., Spracklen, D. V., Mann, G. M., and Chipperfield, M. P.: The relationship between aerosol and cloud drop number concentrations in a global aerosol microphysics model, Atmos. Chem. Phys., 9, 4131-4144, doi:10.5194/acp-9- 
4131-2009, 2009.

Quaas, J., Ming, Y., Menon, S., Takemura, T., Wang, M., Penner, J. E., Gettelman, A., Lohmann, U., Bellouin, N., Boucher, O., Sayer, A. M., Thomas, G. E., McComiskey, A., Feingold, G., Hoose, C., Kristjánsson, J. E., Liu, X., Balkanski, Y., Donner, L. J., Ginoux, P. A., Stier, P., Grandey, B., Feichter, J., Sednev, I., Bauer, S. E., Koch, D., Grainger, R. G., Kirkevåg, A., Iversen, T., Seland, Ø., Easter, R., Ghan, S. J., Rasch, P. J., Morrison, H., Lamarque, J.-F., Iacono, M. J., Kinne, S., and Schulz, M.: Aerosol indirect effects general circulation model intercomparison and evaluation with satellite data, Atmos. Chem. Phys., 9, 8697-8717, doi:10.5194/acp-9-8697-2009, 2009.

Radke, L. and Hobbs, P.: Humidity and particle fields around some small cumulus clouds, J. Atmos. Sci., 48, 1190-1193, 1990.

Reutter, P., Su, H., Trentmann, J., Simmel, M., Rose, D., Gunthe, S. S., Wernli, H., Andreae, M. O., and Pöschl, U.: Aerosoland updraft-limited regimes of cloud droplet formation: influence of particle number, size and hygroscopicity on the activation of cloud condensation nuclei (CCN), Atmos. Chem. Phys., 9, 7067-7080, doi:10.5194/acp-9-7067-2009, 2009.

Riemer, N., Vogel, H., Vogel, B., and Fiedler, F.: Modeling aerosols on the mesoscale- $\gamma$ : Treatment of soot aerosol and its radiative effects, J. Geophys. Res., 109, 4601, doi:10.1029/2003JD003448, 2003.

Rosenfeld, D., Lohmann, U., Raga, G. B., O’Dowd, C. D., Kulmala, M., Fuzzi, S., Reissell, A., and Andreae, M. O.: Flood or drought: how do aerosols affect precipitation?, Science, 321, 1309-1313, 2008.

Sandu, I., Brenguier, J.-L., Geoffroy, O., Thouron, O., and Masson, V.: Aerosol impacts on the diurnal cycle of marine stratocumulus, J. Atmos. Sci., 65, 2705-2718, 2008.

Sandu, I., Brenguier, J.-L., Thouron, O., and Stevens, B.: How important is the vertical structure for the representation of aerosol impacts on the diurnal cycle of marine stratocumulus?, Atmos. Chem. Phys., 9, 4039-4052, doi:10.5194/acp-9-4039-2009, 2009.

Seifert, A. and Beheng, K. D.: A double-moment parameterization for simulating autoconversion, accretion and selfcollection, Atmos. Res., 59-60, 265-281, 2001.

Seifert, A. and Beheng, K. D.: A two-moment cloud microphysics parameterization for mixed-phase clouds. Part 2: Maritime vs. continental deep convective storms, Meteorol. Atmos. Phys., 92, 67-82, 2006a.

Seifert, A., Khain, A., Pokrovsky, A. and Beheng, K. D.: A comparison of spectral bin and two-moment bulk mixed-phase cloud microphysics, Atmos. Res., 80, 46-66, 2006b.

Seinfeld, J. H. and Pandis, S. N.: Atmospheric Chemistry and Physics, John Wiley \& Sons, Inc, Hoboken, 2006.

Small, J. D., Chuang, P. Y., Feingold, G., and Jiang, H.: Can aerosol decrease cloud lifetime?, Geophys. Res. Lett., 36, L16806, doi:10.1029/2009GL038888, 2009.
Sorooshian, A., Feingold, G., Lebsock, M. D., Jiang, H., and Stephens, G. L.: On the precipitation susceptibility of clouds to aerosol perturbations, J. Geophys. Res., 36, L13803, doi:10.1029/2009GL038993, 2009.

Sorooshian, A., Feingold, G., Lebsock, M. D., Jiang, H., and Stephens, G. L.: Deconstructing the precipitation susceptibility construct: improving methodology for aerosolcloud precipitation studies, J. Geophys. Res., 115, D17201, doi:10.1029/2009JD013426, 2010.

Steppeler, J., Doms, G., Schaettler, U., Bitzer, H., Gassmann, A., Damrath, U., and Gregoric, G.: Meso gamma scale forecasts using the nonhydrostatic model LM, Meteorol. Atmos. Phys., 82, 75-96, 2003.

Stevens, B. and Feingold, G.: Untangling aerosol effects on clouds and precipitation in a buffered system, Nature, 461, 607-613, 2009.

Storelvmo, T., Kristjánsson, J. E., Ghan, S. J., Kirkeva, A., and Iversen, T.: Predicting cloud droplet number concentration in Community Atmosphere Model (CAM)-Oslo, J. Geophys. Res., 111, 1-14, 2006.

Storelvmo, T., Kristjánsson, J. E., and Lohmann, U.: Aerosol influence on mixed-phase clouds in CAM-Oslo, J. Atmos. Sci., 65, 3214-3230, 2008.

Tiedtke, M.: A Comprehensive mass flux scheme for cumulus parametrization in large-scale models, Mon. Weather Rev., 117, 1779-1800, 1989.

Twohy, C. H., Clement, C. F., Gandrud, B. W., Weinheimer, A. J., Campos, T. L., Baumgardner, D., Brune, W. H., Faloona, I., Sachse, G. W., Vay, S. A., and Tan, D.: Deep convection as a source of new particles in the midlatitude upper troposphere, J. Geophys. Res., 107(D21), 4560, doi:10.1029/2001JD000323, 2002.

Twomey, S.: The nuclei of natural clouds formation. Part II: The supersaturation in natural clouds and the variation of cloud droplet concentration, Pure Appl. Geophys., 43, 243-249, 1959.

Vogel, B., Vogel, H., Bumer, D., Bangert, M., Lundgren, K., Rinke, R., and Stanelle, T.: The comprehensive model system COSMOART Radiative impact of aerosol on the state of the atmosphere on the regional scale, Atmos. Chem. Phys., 9, 8661-8680, doi:10.5194/acp-9-8661-2009, 2009.

Weigelt, A., Hermann, M., Van Velthoven, P. F. J., Brenninkmeijer, C. A. M., Schlaf, G., Zahn, A., and Wiedensohler, A.: Influence of clouds on aerosol particle number concentrations in the upper troposphere, J. Geophys. Res., 114, D01204, doi:10.1029/2008JD009805, 2009.

Zhang, Y.: Online-coupled meteorology and chemistry models: history, current status, and outlook, Atmos. Chem. Phys., 8, 2895 2932, doi:10.5194/acp-8-2895-2008, 2008. 